\title{
Students' Perception of Teaching Learning Method in Dissection and Histology Lab
}

\author{
Dr. Amar Jayanthi A, Dr. Sajna M V and Benson Benjamin
}

\begin{abstract}
:
Objectives: The purpose of this study was to examine the student perceptions about learning anatomy in dissection and histology lab. Methods: A cross sectional study was carried out among medical students using structured questionnaire related to utilization and effective use of practical hours. Analysed using epi info. Results: Students' views of practical session utilization were not unanimous. Many participants revealed that the practical hours were not utilized effectively. There was no proper formal orientation offered to most of the participants. A significant number of participants received good faculty guidance during their course. Participants suggested a small group learning in histology lab. Conclusions: This study had provided useful information for a review in the allocation of time for practical sessions. There is a need to prepare the students mentally and emotionally before entering the practical lab. Learning anatomy through dissection and histology, discussion of the related topics by expert faculty, supported by computer assistance and reference books in the practical lab may help to effectively utilize the time of practical sessions.
\end{abstract}

Keywords: Dissection lab, Histology lab, Students' perception, utilization of anatomy hours, students' feed back

\section{Introduction}

Anatomy is one of the first and hardest subject in medical education that students face. The amount of information collected in ten months time is more. Of the total 650 hours $80 \%$ of time is consumed by anatomy practicals. Are we utilizing this valuable time effectively to get maximum involvement of students and make them actively participate in learning?. In students perspective the answer was a big fat no. The three hours one spends in that hall is consumed by sleep, fun and gossiping. This constant exposure to non productive routine makes him lazy and over time he loses his interest in studying and loses his total track on anatomy. Finally anatomy swells to a burden and the student turns to capsule like study pattern just to pass an exam. Students perceive histology classes, as being filled with drawing lessons in a class of 38, without the slightest idea of the practicality of understanding microscopic anatomy. Vision 2015 by Medical Council of India has proposed modifications in the existing curriculum to improve the quality of training. Drake R Lsuggested that curricular model chosen must meet the needs of the institution and its students ${ }^{1}$. Vishram singh stated that by meeting the needs of students, educators can ensure that learners are able to learn what is relevant for them in ways that are appropriate ${ }^{2}$. Students' feed back is a powerful tool in improving the quality of teaching. Pallab K G also states that one of the most important resources for sustaining professional development in teaching is getting feedback from students ${ }^{3}$. Nagar et al reported that curriculum planning and teaching methodology are decided by the senior faculty members but the opinion of the students need to be heard in deciding the curriculum to bring out the best in them ${ }^{4}$.

This study aims to get different types of ideas students have about learning anatomy in dissection and histology lab and how effectively the practical hours can be utilized with maximum involvement of students and to make them actively participate in the learning process.

\section{Objectives}

1. To assess student' s perception of the present method of learning anatomy in practical labs

2. To share their thoughts and suggestions for improving the utilization of practical hours

\section{Materials And Methods}

Cross sectional study was carried out using self administered questionnaire among medical students of Government Medical College, Thrissur, Kerala. Students who have successfully completed first MBBS course were asked to fill up a questionnaire so as to get their views regarding the present method of practical sessions in anatomy. Each student was explained the objective of the study and a questionnaire which consisted of orientation before the first visit to dissection and histology lab, duration of dissection and histology practical sessions, how they spend the practical hours, guidance from the faculty, opinion regarding the practical manual and suggestions to improve. A pre-informed consent was taken from each student before answering the questionnaire. Data were collected after getting Institutional research committee and ethical committee 
approval. Confidentiality of the data was maintained. Data coded and entered in excel, analysed using Epi info. Qualitative data analysed using proportions.

\section{Results \& Discussion}

A total of 308 students were included in the study based on the inclusion criteria, of which $60 \%$ $(\mathrm{n}=187)$ were females while $30 \%(\mathrm{n}=93)$ were males which is comparable to the proportion of males and females in the college. In the population $9 \%(\mathrm{n}=28)$ did not reveal their sex. The mean age of participants was $21.58 \pm 1.51$ years. Of the total, $17.2 \%(n=53)$ participants stayed with their parents, $68.5 \%(n=211)$ within the campus in hostel, $7.5 \%(\mathrm{n}=23)$ participants resided as paying guest in near by houses. Among the study participants $6.8 \%(\mathrm{n}=21)$ not responded. The results of the study were discussed under the following two headings, dissection as well as histology.

\section{Dissection}

The basic purpose of dissection is to learn the gross structures for functional correlation ${ }^{5}$.Therefore cadaver dissection forms one of the most important components of anatomy, as it helps the students to remember and recollect what they have seen. Majority of participants $91.2 \%(n=281)$ believed that learning anatomy by dissection is essential to become a doctor, also the best method of learning human body is by doing dissection. It gives better understanding of the region and helps to recollect a large amount of information. On the other hand, a small group of participants, $6.8 \%(n=21)$ felt that dissection is not essential to become a doctor. They believed that it helps only those opting to become a surgeon. On the importance of dissection in medical education $1.9 \%(\mathrm{n}=6)$ not responded to the question.

\section{1.a Orientation before dissection}

Every student who is entering into the medical profession enters the dissection hall with a lot of doubts and queries. The orientation of such a student can be matched to the same of a kinder garten student in his first class. He is not oriented, is anxious, and overall he is totally ignorant. Abay mulu and Desalgn Tegabu at the university of Gondar studied the attitudinal changes towards cadaver dissection and found that students generally experience emotional reactions when they encounter cadaver dissection for the first time and on subsequent exposure the fear and other symptoms gradually disappear and excitement and interest increases ${ }^{6}$. Gaurav Agnihotri reports that there is a need to prepare the students mentally and emotionally before entering the dissection room, so that they are involved and stimulated ${ }^{7}$.

The results of this study showed that there was no proper formal orientation offered to most $75 \%$ $(n=231)$ of the participants. Figure 1shows the orientation regarding dissection received by students before initial exposure to cadaver. According to $95.5 \%(\mathrm{n}=294)$ of participants such orientations help the students to eliminate the initial fear and aversion towards cadavers, to understand the aims of first MBBS course and also to get an idea of what is expected from them. Bernard et al conducted a survey among medical students of Nigeria concluded that dissection can be improved with early formal orientation before dissection and regular staff assistance ${ }^{8}$.

1.b Utilization of dissection hours: Analysis of how students spent their time during dissection showed that a significantly larger proportion of participants indulge in multiple tasks like discussion with peer group, watch others doing dissection, talking, sitting simply, sleeping. This shows that the three hours is not utilized effectively and to the expected level. Table number 1 shows the utilization pattern of dissection hours. The dissection time can be saved by providing a brief description of the region to be dissected and by demonstration with the help of prosected specimens. When $81.8 \%(\mathrm{n}=252)$ of participants believed that briefing gives an idea of what to learn from that region, $17.2 \%(n=53)$ were against the opinion that students will be uninterested in exploring things when once the briefing is over.

A majority of participants $95.1 \%(\mathrm{n}=293)$ felt that demonstration classes before dissection help them to learn anatomy better. This ensures that students see all the structures without destroying the normal anatomy. Lynn et al revealed that learning anatomy by dissection as well as by peer-mediated teaching had no added benefit in terms of exam performance ${ }^{9}$. Medical students of Gondar University preferred cadaver dissection than prosection and opposed its replacement by other learning methods ${ }^{6}$. They also believe that learning with prosected specimens kills curiosity and loose the surgical skill development.

\section{1.c Faculty guidance in dissection hall}

A good number of medical students show learning difficulties, although they are not linked with low intelligence. These students need psychological and practical support. Angela Rowlands et al feel that the teaching faculty should have an access to information about the needs of these students and how they can be met $^{10}$. In this study $51 \%(\mathrm{n}=157)$ of the participants rated the guidance from the faculty to be good, $25 \%(\mathrm{n}=77)$ 
to be satisfactory, $16.9 \%(\mathrm{n}=52)$ as excellent and $2.9 \%(\mathrm{n}=9)$ to be poor. Multiple response was given by $2.2 \%$ $(\mathrm{n}=7)$ and no response by $1.9 \%(\mathrm{n}=6)$.

In the present scenario dissection consumes continuous 3 hours per day for 5 days in a week. The time allocated for anatomy practicals was sufficient to $54.9 \%(n=169)$ of participants. A reduction in the duration of dissection was suggested by $42.5 \%(n=131)$ of participants as continuous dissection for three hours is tiring and students tend to deviate from dissection and get involved in non productive tasks when duration is long. This makes the students lazy and over time the interest in study decreases and loses total track on anatomy. A short break of 10 minutes during dissection was suggested by $90.6 \%(n=279)$ participants. A small group of participants, $3.9 \%(n=12)$ were of the opinion that such breaks would be distracting. Once dissection is stopped students don't like to restart.

Studies conducted to learn about the effects of music on cognitive performance by Arielle S Doleugi showed that background music promotes cognitive performance while other studies have shown that listening to music while engaged in cognitive tasks can impair performance ${ }^{11}$. Findings of this study reveals that doing dissection in a low volume musical background is distracting to $48.1 \%(\mathrm{n}=148)$ of participants. It diverts attention, loose mood of dissection. Music provides a relaxed atmosphere to $37.7 \%(\mathrm{n}=116)$ participants, has no effect on learning in dissection hall for $14 \%(\mathrm{n}=43)$ participants. The question was not responded by $0.3 \%(\mathrm{n}=1)$ participants. Fazal et al collected student's opinion on the use of computer assisted classes for teaching anatomy. Analysis showed that computer facilitated the anatomy learning in easy manner and increased the understanding of lesson ${ }^{12}$. Daily assessment at the end of dissection is motivating to $76.3 \%(\mathrm{n}=235)$ of participants, to $11.7 \%$ $(n=36)$ it add stress, $5.5 \%(n=17)$ said it will not produce any effect in learning. It creates extra burden and stress to $2.6 \%(n=8)$ of participants.

\section{Histology}

Light microscopic demonstration associated with an hour preview of lectures were used during practical training in histology. Students are expected to identify tissues and organs and understand the structural basis of their function. Such knowledge is essential for understanding disease mechanism in terms of altered structure and functions of the human body. Students perceive the histology classes as being filled with drawing lessons in a class of 38 or 40 , without even the slightest idea of what is happening under the microscope.

\section{2.a Orientation before initial histology Lab}

This study shows that the purpose of learning histology was explained to $46.8 \%$ ( $n=144)$ of participants in the first class, when such an introduction was not received by $30.2 \%(n=93)$ participants. Sixty $(19.5 \%)$ participants did not remember whether such introduction was given and $11(3.6 \%)$ not responded to the question. Among the participants $93.8 \%(n=289)$ had an opinion that an introduction about the importance of histology is essential.

\section{2.b Utilization of histology hours}

In the present scenario the histology session consists of two hours in a week. This two hours is utilised for seeing demonstration slides, studying the tissue, discussion with faculty and with peer group, drawing diagram, talking and for correction of previous diagrams.

Assessment of the way of utilization of histology hours revealed that only a small percentage utilize the time for studying tissues. Most of the time is spent for multiple tasks. Table number 2 shows the present method of utilization of histology hours. The mean time spent for studying tissue is $26.17 \pm 17.08$ minutes and for drawing is $38.38 \pm 26.4$ minutes. So the question is whether there is a need for such a drawing class for medical students. If this time is alternatively used for better understanding of the tissue. The time also can be effectively used for inclusion of the latest innovations in the field of imaging of tissue and organ structures.

\section{2.c Faculty guidance in histology lab}

Excellent teachers serve as role models, influence students and enable students to reach their potential ${ }^{13}$. In histology 37 to 38 students are attended by a single faculty. Participants suggested a small group learning in histology, 6 or 7 students with one faculty allotted to each group. According to $93.2 \%(n=287)$ participants, topic discussion with faculty was good and it gives better understanding, better when nearing exams, 3.6\% $(n=11)$ did not agree with this opinion and 3.2\% $(n=10)$ not responded to the question. The point that has to be highlighted here is that the participants reports that topic discussion with faculty is good but they are not receiving it as expected, this brings in the necessity of posting more faculty for histology discussion and also getting customised and personalised care delivered to the students. A significant proportion of participants considered the effort taken by the teaching faculty to be good $45 \%(n=131)$ as shown in the figure 2 . 


\section{2.d Duration of histology}

There is enough time to study and make a rough drawing of the picture. It is necessary to spend some time studying the tissue. A change in the duration was suggested by $24.7 \%(\mathrm{n}=76)$ participants. In many institutions less importance is given to histology. Students also feel that reducing the duration will make them rush through the topic without any actual understanding. The factor to be noted is that students realize that the time they spent in histology lab is being wasted and the action can either be to modify the time utilization or to reduce the duration and decrease wastage. The histology classes turning into an art class should be prevented at any cost and the study significantly proves this fact. Lab-lecture-Conference sequence introduced by Amos G Gona, starting with pre-lab presentation followed by students studying the basic histological features and discussion of clinically relevant topics, effectively reduces the time for histology ${ }^{14}$.

Students were asked to grade the difficultness of learning microanatomy from 1 to 5 (very easy to very difficult). The most responded score was 3 by $55.5 \%(n=171)$ of participants with a mean score of $3.1 \pm 0.9$, showing that histology learning is not easy at the same time not that difficult. Participants suggested a greater need for additional resources such as atlases, audiovisual aids, computer based teaching in the lab, teleconferencing in anatomy giving emphasis to clinically oriented knowledge gaining. The above statements are backed by the participant data which says $83.8 \%(\mathrm{n}=258)$ were of the opinion that computer based learning, in addition to the traditional teaching method in histology is useful as it gives an idea about how an ideal tissue would look like and also all structures could be seen and appreciated. Computer based learning was not accepted by $11.7 \%(n=36)$ as it masks the normal appearance of tissues and $4.5 \%(n=14)$ refused to answer the question.

\section{Conclusion}

The study lays a foundation for change in the present system of utilization. In this student friendly era, changes in anatomy learning has to be adopted to schedule the practical hours so that students are most benefited, enabling students to learn and utilise time and resources effectively.

\section{Acknowledgement}

We wish to thank the students of Government medical college, Thrissur, who participated in this study. Financial support was provided through the Institutional Research Committee of the college.

\section{References}

[1]. Drake RL. Anatomy education in a changing medical curriculum. Kaibogaku Zasshi. 1999 Aug;74 (4):487-90.

[2]. Vishram Singh and Poonam Kharb. A paradigm shift from teaching to learning gross anatomy: meta-analysis of implications for instructional methods. The journal of anatomical society of India.2013; 62: $84-89$.

[3]. Pallab K. Ganguly. Teaching and Learning of Anatomy in the 21st Century: Direction and the Strategies. The Open Medical Education Journal. 2010; 3: 5-10.

[4]. S K Nagar, Ojaswini Malukar, Dharti Kubavat, Vipul Prajapati,Dimple Ganatra, Ajay Rathwa. Students' perception on anatomy teaching methodologies. National Journal of Medical Research. Jan - March 2012; Volume 2 Issue 1:111-112.

[5]. Gayatri Rath. Krishna Garg. Inception of cadaver dissection and its relevance in present day scenario of medical education. Journal of Indian Medical Association. July2006; 104 (6): 331-33

[6]. Abay Mulu and Desalegn Tegabu. Medical students' attitudinal changes towards cadaver dissection: A longitudinal study. Ethiop J Health Sci. March 2012; Vol.22 (1): 51-58.

[7]. Gaurav Agnihotri, Mandeep Gill Sago. Reactions of first year Indian Medical Students to the dissection hall experience. NJIRM. 2010; Vol.1(4): oct - Dec 4-9.

[8]. Emue Ewonu Bari Bernard, Danlodi Sambo Amaza, Aniah Julius Akomaye, Onwih Etim Efiong. Knowledge, Attitude and practice of Nigerian preclinical students to cadaver dissection. IOSR Journal of Dental and Medical Sciences. Nov-Dec 2012; Vol 2 (5): 33 36.

[9]. Lynn Ashdown, Evan Lewis, Maxwell Hincke, and Alireza Jalali I. Learning Anatomy: Can Dissection and Peer-Mediated Teaching Offer Added Benefits over Prosection Alone? International Scholarly Research Notices. 2013; Article ID 873825: 4pages.

[10]. Angela Rowlands, Stephen Abbott, Grazia Bevere, Christopher M Roberts. Medical students' perceptions and understanding of their specific learning difficulties. International Journal of Medical Education. 2013; 4: 200-206.

[11]. Arielle S. Dolegui. The Impact of Listening to Music on Cognitive Performance. Student pulse, the international student journal. 2013, Vol. 5 NO, 09: 1-2.

[12]. Fazal-Ur-Rehman, Sheeba Nuzhat Khan, S. Mobashir Yunus. Students, perception of computer assisted teaching and learning of anatomy- in a scenario where cadavers are lacking. Biomedical Research 2012; 23 (2): 215-218

[13]. Samy A Azer. The qualities of a good teacher: how can they be acquired and sustained?. J R Soc Med. 2005 February; 98 (2): $67-$ 69.

[14]. Amos G Gona, Peter B Berendsen and Elizabeth A Alger. New approach to teaching histology. Medical Science Educator. 2012; vol 15: no.2. 
Figure 1. Showing the orientation regarding dissection received by students before their first encounter with cadaver.

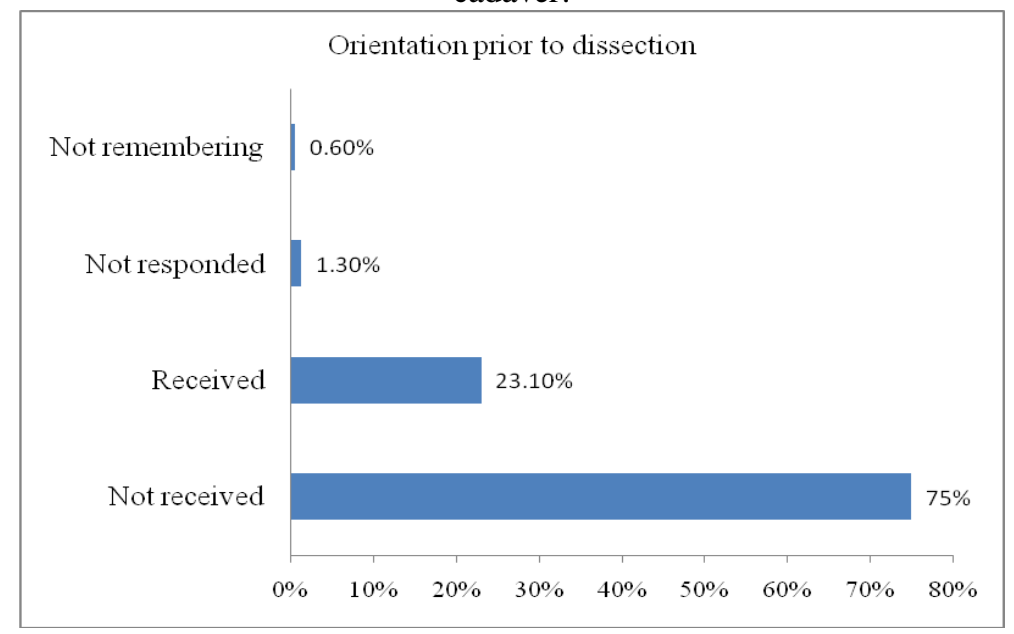

Figure: 2 Perceived grading of efforts taken by the teachers for histology

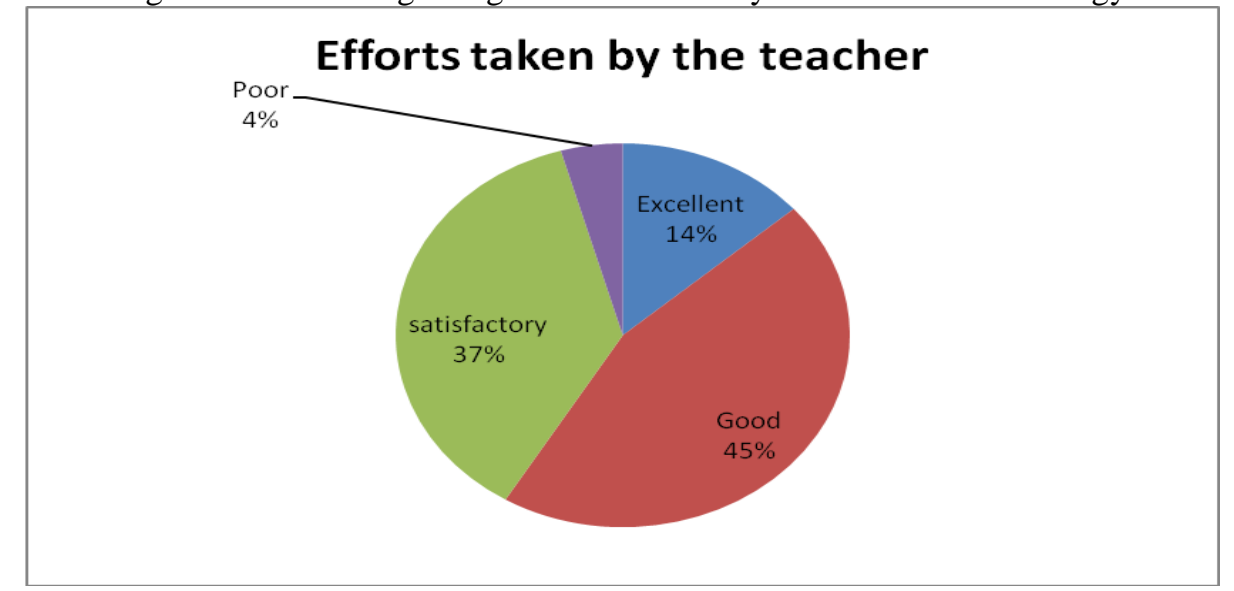

Table no:1 Utilization pattern of dissection hours among the students

\begin{tabular}{|c|c|c|}
\hline Mode of utilization & $\begin{array}{c}\text { First half } \\
\text { No(\%) }\end{array}$ & $\begin{array}{c}\text { Second half } \\
\text { No(\%) }\end{array}$ \\
\hline Reading Cunningham & $34(11 \%)$ & $4(1 \%)$ \\
\hline Doing Dissection & $18(5.8 \%)$ & $98(31.8 \%)$ \\
\hline Watching dissection & $7(2.3 \%)$ & $12(3.9 \%)$ \\
\hline Breifing by the faculty & $62(20.1 \%)$ & $11(3.6 \%)$ \\
\hline Peer group discussion & $11(3.6 \%)$ & $9(2.9 \%)$ \\
\hline $\begin{array}{c}\text { Multiple activities like- talking,sitting } \\
\text { simply, sleeping }\end{array}$ & $158(51.3 \%)$ & $154(50 \%)$ \\
\hline Not responded & $18(5.8 \%)$ & $20(6.5 \%)$ \\
\hline
\end{tabular}

Table no:2 Present utilization pattern of histology hours among the students

\begin{tabular}{|c|c|c|}
\hline Mode of utilization & $\begin{array}{c}\text { First half } \\
\mathbf{N = 3 0 8}\end{array}$ & $\begin{array}{c}\text { Second half } \\
\mathbf{N = 3 0 8}\end{array}$ \\
\hline Preview & $51(16.6 \%)$ & $6(1.9 \%)$ \\
\hline Preview and Demonstration of slides & $91(29.5 \%)$ & $7(2.3 \%)$ \\
\hline Drawing diagram & 0 & $83(26.9 \%)$ \\
\hline Drawing, Peer group discussion and talking & 0 & $13(4.2 \%)$ \\
\hline Correcting previous slides & $62(20.1 \%)$ & 0 \\
\hline Drawing and Correcting previous slides & 0 & $78(25.3 \%)$ \\
\hline Not responded & $27(8.8 \%)$ & $14(4.5 \%)$ \\
\hline $\begin{array}{c}\text { Multiple activities- drawing, talking, } \\
\text { peer group discussion }\end{array}$ & $77(25 \%)$ & $107(34.7 \%)$ \\
\hline
\end{tabular}

